\title{
PERAN PEREMPUAN DALAM PENCEGAHAN KEKERASAN TERORISME DAN RADIKALISME
}

\author{
Adang Darmawan Achmad, Hudzaifah Achmad Qotadah ${ }^{2} *$ Muhammad $^{1}$ \\ Sophy Abdul Aziz ${ }^{3}$, Abdurrahman Achmad Al Anshary ${ }^{4}$ \\ ${ }^{1}$ Universitas Mubammadiyah Cirebon, Indonesia \\ ${ }^{2}$ University of Malaya, Malaysia, Malaysia \\ ${ }^{3}$ International Islamic University Malaysia, Malaysia \\ ${ }^{4}$ Islamic University of Madinah, Saudi Arabia \\ * Correspondence: hudzaifahachmad47@gmail.com
}

Received: 07 Agustus 2020; Accepted: 28 September 2021; Published: 30 September 2021

\begin{abstract}
There have been several instances of terrorism in Indonesia, including multiple suicide bombs, shootings, and other acts that have threatened public safety and impeded governmental functions. This issue has resulted in anxiety and insecurity, posing a threat to people's lives, particularly women's. As a result, all parties involved, especially women, must take adequate measures to anticipate and address these issues. Women are one of the possible individuals who can play a strategic role in limiting the spread of violent terrorism and extremism. They are also one of the most vulnerable groups. A thorough qualitative method is used in this article to examine the role of women in averting violent terrorism and radicalism. Following the findings of the study, it was discovered that a woman can play a significant role in violence prevention if she can create a happy home environment that always promotes good and moderate religious values that are in accordance with the real teachings of Islam. Thus, individuals and families are the primary representatives of either the anti-terrorism and anti-radicalization awareness campaign.
\end{abstract}

Keywords: women; prevention; terrorism; radicalism.

\begin{abstract}
Abstrak
Di berbagai daerah di Indonesia, telah banyak terjadi serangkaian peristiwa ekstremisme radikal, termasuk bom bunuh diri, penembakan, dan lain sebagainya yang mengusik keselamatan masyarakat dan kegiatan pemerintah. Fenomena ini jelas melahirkan rasa takut dan ketidakamanan yang mengusik berbagai elemen kehidupan masyarakat. Karenanya, pihak terkait, termasuk perempuan, perlu melakukan respon yang tepat untuk menyelesaikan permasalahan tersebut. Perempuan dapat menjadi salah satu figur potensial yang mempunyai peran strategis dalam membantu pencegahan terorisme, kekerasan dan radikalisme. Penelitian ini berfokus pada peran perempuan dalam pencegahan kekerasan terorisme dan radikalisme di mana penulis menggunakan metode kualitatif penuh dengan merujuk kepada sumber-sumber yang berkaitan dengan topik penelitian dan kemudian dianalisis secara deskriptif. Hasil penelitian menyatakan bahwa seorang perempuan berperan penting dalam pencegahan kekerasan jika per-
\end{abstract}


empuan tersebut mampu membangun lingkungan kehidupan keluarga yang harmonis dan senantiasa menekankan norma-norma keagamaan yang baik dan moderat sesuai dengan ajaran Islam yang sebenarnya. Maka, individu dan keluarga merupakan pendukung utama program kewaspadaan terhadap bahaya terorisme dan radikalisme.

Kata-kata kunci: perempuan; pencegahan; terorisme; radikalisme.

\section{Pendahuluan}

Saat ini kehidupan masyarakat yang damai, aman, tertib dan harmonis mulai terganggu dengan lahirnya fenomena radikalisme dan aksi terorisme. Aksi terorisme yang terjadi di Indonesia sebenarnya berawal dari masuknya doktrindoktrin ekstrem, bahkan menggunakan cara-cara radikal dan kekerasan untuk melakukan perubahan atau reformasi politik dan sosial yang drastis. ${ }^{1}$ Radikalisme dan terorisme merupakan fenomena dalam kehidupan berbangsa dan bernegara yang melibatkan hubungan antara warga negara dan negara. Di era modern sekarang ini, isu aktivisme dan terorisme tidak hanya melibatkan jaringan lokal, tetapi juga kelompok dan jaringan internasional. ${ }^{2}$

Salah satu aksi radikalisme dan terorisme yang masih menyisakan luka di hati masyarakat Indonesia adalah tragedi bom Bali yang masih menjadi salah satu tragedi terbesar yang dilakukan oleh kelompok teroris. ${ }^{3}$ Oleh karena itu, fenomena radikalisme dan ekstremisme selalu menjadi topik hangat yang tak kunjung padam.

Dalam budaya patriarki, perempuan dipandang memiliki kelebihan tersendiri, yakni persepsi bahwa perempuan dianggap tidak berbahaya dibandingkan laki-laki, seperti yang terjadi belakangan ini di Indonesia. Rakyat Indonesia kembali dikejutkan oleh seorang wanita tak dikenal yang sedang berjalan melewati halaman Mabes Polri dan kemudian menodongkan pistol ke depan Mabes Polri. Oleh karena itu, nilai peran perempuan telah berubah, yang berarti mereka dapat melakukan hal yang sama seperti laki-laki, bahkan melakukan perilaku kekerasan.

Adapun penelitian yang mengkaji persoalan perempuan dan radikalisme sudah banyak dilakukan, begitu juga dengan peran perempuan dalam menang-

1 Ali Masyhar and Ridwan Arifin, "Urgensi Pembentengan Masyarakat Dari Radikalisme Dan Terorisme (Upaya Terhadap Jamiyyah Nahdlatul Ulama Kecamatan Bonang Kabupaten Demak)," Jurnal Pengabdian Hukum Indonesia (Indonesian Journal of Legal Community Engagement) JPHI 1, no. 01 (2018): 1-12, https://journal.unnes.ac.id/sju/index.php/JPHI/article /view/27259.

2 Anzar Abdullah, "Gerakan Radikalisme Dalam Islam: Perspektif Historis," Addin 10, no. 1 (2016): 1-28, https://doi.org/10.21043/addin.v10i1.1127.

3 Arief Rifkiawan Hamzah, "Radikalisme Dan Toleransi Berbasis Islam Nusantara," Sosiologi Reflektif 13, no. 1 (2018): 19-35, http://ejournal.uin-suka.ac.id/isoshum/sosiologireflektif /article/view/131-03/1297. 
gulangi persoalan radikalisme, misalnya; Pertama, penelitian yang dilakukan oleh Christin Rajagukguk mengenai "Feminisme Kultural dan Peran Perempuan dalam Deradikalisasi di Indonesia". ${ }^{4}$ Fokus penelitian ini adalah pada upaya BNPT untuk melibatkan karakter perempuan dalam proses deradikalisasi melalui berbagai organisasi perempuan. Hasil penelitian menemukan bahwa feminisme perempuan diperlukan ketika mencari informasi dari napiter.

Kedua, penelitian tentang "Potensi Peran Perempuan dalam Mewujudkan Moderasi Beragama di Indonesia" yang ditulis oleh Luh Riniti Rahayu. ${ }^{5}$ Menurut Rahayu, pemerintah telah melakukan berbagai upaya untuk mengatasi permasalahan intoleransi, akan tetapi sikap intoleransi semakin meningkat diberbagai daerah dan tentu saja persoalan ini berbahaya bagi kenyamanan kehidupan sosial dan beragama masyarakat Indonesia. Karenanya, dengan melakukan penelitian tersebut, Rahayu mendapati bahwa keterlibatan perempuan sangat potensial dalam mengatasi persoalan intoleransi sehingga diharapkan mampu menjaga kerukunan umar beragama di Indonesia.

Ketiga, kajian yang dikaji oleh Najahan Musyafak mengenai "Peran Perempuan Dalam Pencegahan Radikalisme". ${ }^{6}$ Penelitian ini mencoba untuk mengkaji peran perempuan di ranah domestik dalam menanggulangi radikalisme dengan mewancarai beberapa narasumber perempuan dari berbagai latar belakang pendidikan, dan kepercayaan. Hasil penelitian mendapati bahwa hakikatnya perempuan memiliki pemahaman yang memadai mengenai karakteristik gerakan radikal yang memungkinkan mereka untuk melakukan antisipasi dalam melawan perilaku-perilaku radikal.

Berdasarkan beberapa penelitian yang pernah dilakukan mengenai wanita dan radikalisme, menunjukkan bahwa berbagai upaya dan usaha telah dilakukan dalam rangka mencegah, mengurangi, serta menanggulangi persoalan radikalisme dan ekstremisme. Usaha dan upaya tersebut dilakukan dengan melibatkan banyak kalangan, tidak terkecuali menyertakaan dan melibatkan peranan kaum wanita dalam mengatasi persoalan radikalisme dan ekstremisme. Penelitian ini akan fokus pada pembahasan perspektif Islam mengenai peranan serta kontribusi wanita dalam memenuhi upaya dan usaha pencegahan radikalisme yang mana sejatinya seorang wanita merupakan sosok terdekat bagi keluarganya dalam membentuk perilaku, adat kebiasaan, dan lain sebagainya.

4 Christin Rajagukguk, "Feminisme Kultural Dan Peran Perempuan Dalam Deradikalisasi Di Indonesia," Journal of International Relations 4, no. 4 (2018): 775-83.

5 Luh Riniti Rahayu and Putu Surya Wedra Lesmana, "Potensi Peran Perempuan Dalam Mewujudkan Moderasi Beragama Di Indonesia," Pustaka: Jurnal Ilmu-Ilmu Budaya 20, no. 1 (2020): 31-37, https://doi.org/10.24843/pjiib.2020.v20.i01.p05.

6 Najahan Musyafak, "Peran Perempuan Dalam Pencegahan Radikalisme," Jurnal Dakwah 21, no. 1 (2020): 85-110, https://doi.org/10.14421/jd.2112020.6. 


\section{Metodologi}

Penulis menggunakan metode kualitatif yang mana penelitian kualitatif sering menjadi dasar asumsi penelitian dalam bidang ilmu syariat, ilmu sosial, dan ilmu humaniora. Penelitian ini adalah penelitian kepustakaan (library research) dari beberapa tulisan para peneliti sebelumnya yang kemudian dianalisis secara deskriptif dengan metode deduktif dan induktif.

\section{Hasil dan Pembahasan \\ Kedudukan Wanita Sebelum dan Setelah Islam}

Sebelum kedatangan Islam, wanita dipandang hina, misalnya saja di Athena, kedudukan wanita Athena selalu dipandang lebih rendah di mana mereka harus tunduk terhadap laki-laki. Wanita Romawi digambarkan oleh para ahli sejarah sebagai bayi, makhluk rendah, anak kecil, seseorang yang tidak mampu melakukan sesuatu sesuai dengan keinginannya dan lain sebagainya. Begitu pun perlakuan orang Quraisy di mana setiap keluarga yang melahirkan anak perempuan akan dibunuh ketika baru melahirkan. ${ }^{7}$ Firman-Nya:

"Dan apabila seseorang dari mereka diberi kabar dengan (kelahiran) anak perempuan, hitamlah (merah padamlah) mukanya, dan dia sangat marah. Ia menyembunyikan dirinya dari orang banyak, disebabkan buruknya berita yang disampaikan kepadanya. Apakah dia akan memeliharanya dengan menanggung kehinaan ataukah akan menguburkannya ke dalam tanah (hidup-hidup)?. Ketahuilah, alangkah buruknya apa yang mereka tetapkan itu." (Q.S: An-Nahl: 58-59).

Wanita pada saat itu tidak terbela dan tidak diberikan hak yang sewajarnya di mana mereka di anggap rendah dan mereka pun tidak diberikan kebebasan untuk menentukan nasi dan masa depan mereka sendiri. Mereka juga tidak mendapat tempat di sisi masyarakat di mana mereka diperlakukan sebagai rakyat kelas dua. Selain itu, di masa jahiliyah wanita hanya dianggap sebagai sebuah benda yang tidak bernilai dan hanya sebagai alat pemuas nafsu saja sehingga mereka menderita dan tidak bernilai sama sekali. Hal demikian ini terlihat bagaimana seorang suami akan menyediakan terlebih dahulu sebuah lubang ketika istrinya hamil untuk menguburkan anak perempuan mereka secara hiduphidu, bertujuan untuk menjauhkan dari perkara yang memalukan di kemudian hari dan takut menanggung beban hidup serta kemiskinan. Dan masih banyak lagi berbagai bukti atau pun contoh yang memperlihatkan bagaimana kedudukan wanita di masa sebelum kedatangan Islam. ${ }^{8}$

\footnotetext{
Jamal Badawi, “The Status of Women in Islam,” Journal Al-Ittihad 8, no. 2 (1971).

8 Che Zarrina binti Sa'ari and Joni Tamkin bin Borhan, "Peranan Wanita Dalam Pengukuhan Akidah Umat Islam," Jurnal Usuluddin 23, no. 24 (2015): 35-50.
} 
Islam merupakan agama rabmatan lil alamin, bertujuan untuk menyempurnakan akhlak manusia dan menjadi pedoman bagi umatnya agar menjadi manusia yang rukun dan damai. Keberadaan Islam telah meningkatkan derajat dan perlakuan manusia terhadap perempuan di mana Allah SWT menetapkan bahwa perempuandan laki-laki memiliki kedudukan yang sama dalam Islam. ${ }^{9}$ Firman-Nya:

"Hai sekalian manusia, bertakwalah kepada Tuhan-mu yang telah menciptakan kamu dari seorang diri, dan dari padanya Allah menciptakan isterinya; dan dari pada keduanya Allah memperkembang biakkan laki-laki dan perempuan yang banyak. Dan bertakwalah kepada Allah yang dengan (mempergunakan) nama-Nya kamu saling meminta satu sama lain, dan (peliharalah) hubungan silaturrahim. Sesungguhnya Allah selalu menjaga dan mengawasi kamu." (Q.S: An-Nisa: 1)

Islam juga memberikan bukti yang jelas bahwa perempuan pada kenyataannya setara dengan laki-laki dalam pelaksanaan hak dan kewajiban seperti shalat, zakat, puasa, haji, dll. dihadapan Allah SWT. Dalam Al-Qur'an dinyatakan:

"Dan aku tidak menciptakan jin dan manusia melainkan supaya mereka mengabdi kepada-Ku.” (Q.S: Adz-Dzariyat: 56)

Dan juga,

"Tiap-tiap diri bertanggung jawab atas apa yang telah diperbuatnya." (Q.S: Al-Muddatstir: 38)

Maka, dengan status serta kedudukan yang telah diberikan kepada kaum wanita, agama Islam telah meletakan wanita kedalam suatu kedudukan yang terjamin. Dalam sejarah Islam memperlihatkan bahwa wanita memliki peranann yang besar dan krusial. Wanita muslimah di era Rasulullah SAW mendedikasikan sebagian besar untuk suami, anggota keluarga atau umat Islam. Misalnya Saidatuna Khadijah Ummu al-Mu minin yang menjadi sumber kekuatan bagi Nabi Muhammad SAW ketika menghadapi berbagai kesulitan atau ancaman dari kaum Quraisy yang ingin membunuh beliau dan tatkala beliau merasa cemas dan takut, Khadijah memainkan peran untuk menenangkannya. Selain itu, perempuan juga ikut membantu dalam misi dakwah Islam. Pada masa itu pun, banyak dari kaum wanita yang telah ikut menyertai Rasullulah SAW dalam beberapa peperangan besar yang pada asanya bertujuan untuk menegakan serta membela baik agamanya, dirinya, keluarganya dan umat Islam. ${ }^{10}$

9 Abdullah Haji Hassan Alwi, “Islam Dan Wanita," Jurnal Usuluddin 4, no. 4 (2015): 105-16.

10 Asyraf $\mathrm{Hj}$ Ab Rahman, Wan Ibrahim Wan Ahmad, and Zainab Ismail, "Peranan Wanita Dalam Pembangunan Keluarga Dari Perspektif Fi Zilal Al- Quran,” JGD-Journal of Governance and Development 6 (2010): 14-21, http:/ / repo.uum.edu.my/11919/1/13.pdf. 


\section{Radikalisme dan Terorisme}

Secara terminologis, radialisme dimaknai sebagai paham yang ditandai oleh empat unsur yang semuanya berkarakteristik, yaitu (1) tidak toleran dan tidak menghargai pendapat atau keyakinan orang lain, (2) sikap fanatik yang mengarah pada kebenaran. perasaan terhadap diri sendiri dan menganggap partai sebagai orang lain adalah salah, (3) sikap eksklusif yang berbeda dengan yang dilakukan kebanyakan orang pada umumnya, (4) sikap revolusioner yang cenderung menggunakan kekerasan untuk mencapai tujuan yang diinginkan. ${ }^{11}$

Yusuf alQaradhai menggunakan istilah al-Tataarruf ad-Din untuk mengartikan radikalisme yang berarti salah melaksanakan ajaran agama atau mengamalkan ajaran agama, dan posisi tarf (marginal) jauh dari esensi ajaran Islam yang disyaratkan oleh syariat Islam. ${ }^{12}$ Radikalisme dalam agama ibarat pisau bermata dua. Anda dapat memperoleh makna positif dari radikalisme. Inilah semangat perubahan ke arah yang lebih baik, atau disebut Islab (perbaikan) atau tajdid (pembaruan). ${ }^{13}$ Di sisi lain, dapat menjadi berbahaya ketika mencapai tahap ghuluw (berlebihan) dan ifrath (berlebihan), menggunakan kekerasan atau pemaksaan terhadap pemeluk agama lain untuk memperoleh penerimaan dan keyakinan terhadap keyakinan agama yang diterima. ${ }^{14}$

Adapun definisi terorisme hingga saat ini masih menjadi sebuah perdebatan, belum terdapat definisi terorsime yang diterima secara universal, meskipun banyak pakar ahli yang telah merumuskan. Hal tersebut karena upaya mendefinisikan terorisme tidak dapat dilepaskan daripada berbagai kepentingan baik kepentingan ideologi mahupun politik. ${ }^{15}$ Secara etimologis terorisme berasal daripada kata terrere (Latin) yang bermaksud menyebabkan orang gemetar atau dimaksudkan untuk membuat orang takut. ${ }^{16}$

Menurut KBBI, teror ialah sebuah usaha untuk menciptakan ketakutan dan kekejaman yang dilakukan oleh individu atau kelompok. Sedangkan teroris bermakna seseorang yang menggunakan kekerasan bertujuan meciptakan rasa takut dan terorisme merupakan penggunaan kekerasaan untuk melahirkan ketakutan dalam usaha mencapai suatu tujuan terutamanya tujuan politik.

11 Emna Laisa, "Islam Dan Radikalisme," Islamuna: Jurnal Studi Islam 1, no. 1 (2014): 1-18, https://doi.org/10.19105/islamuna.v1i1.554.

12 Abdullah, "Gerakan Radikalisme Dalam Islam: Perspektif Historis."

13 Masyhar and Arifin, "Urgensi Pembentengan Masyarakat Dari Radikalisme Dan Terorisme (Upaya Terhadap Jamiyyah Nahdlatul Ulama Kecamatan Bonang Kabupaten Demak)."

14 A Faiz Yunus, "Radikalisme, Liberalisme Dan Terorisme: Pengaruhnya Terhadap Agama Islam,” Jurnal Studi Al-Qur an: Membangun Tradisi Berfikir Qur'ani 13, no. 1 (2017): 76-94, https://doi.org/10.21009/jsq.013.1.06.

15 Zulfi Mubarak, "Fenomena Terorisme Di Indonesia," Salam: Jurnal Studi Masyarakat Islam 15, no. 2 (2012): 240-54.

16 Abdul Muis Naharong, “Terorisme Atas Nama Agama," Refleksi 13, no. 5 (2014): 593-622, https://doi.org/10.15408/ref.v13i5.915. 
Dengan demikian, dapat disimpulkan bahwa radikalisme adalah pandangan atau cara berfikir seseorang yang radix iatu mendalam hingga kepada akarnya bertujuan untuk mencapai tujuan tertentu yang dikehendakinya. Sedangkan terorisme merupakan sebuah aktifitas kekerasan bertujuan menimbulkan rasa teror atau takut terhadap orang lain baik yang dilakukan secara perorangan ataupun kelompok untuk mencapai tujuan tertentu.

\section{Radikalisme dan Terorisme Menurut Persepktif Islam}

Islam menjadi satu-satunya agama Samawi yang mendapat penjagaan keasliannya serta kemurniaanya di mana agama Nasrani dan agama Yahui telah tidak murni lagi dan keluar dari bentukmya yang asli sebagai agama Samawi. ${ }^{17}$ Kata Islam sendiri bermakna memeilihara diri, tunduk patuh dan taat sehingga ketika seorang individu yang telah masuk Islam dinamakan Muslim di mana ia telah menyatakan dirinya telah taat, menyerahkan diri, dan patuh pada setiap ajaran dan perintah-Nya. ${ }^{18}$

"(Ingatlah) ketika Tuhannya berfirman kepadanya: "Serahkanlah diri (kepadaKu wahai Ibrahim)!" Nabi Ibrahim menjawab: "Aku serahkan diri (tunduk taat) kepada Tuhan Yang Memelihara dan mentadbirkan sekalian alam". (Q.S: Al-Baqarah: 131)

Islam juga merupakan agama yang dijamin oleh Allah SWT di mana senantiasa memperkenankan hamba-hambanya menggunakan akalnya untuk memahami perkataan-Nya yang terkandung dalam Al-Qur'an, agar terhindar dari penyimpangan dan ketidaksesuaian keyakinan agama dan ajaran Islam yang benar yang mana Islam merupakan agama yang mengajarkan keseimbangan antara dunia dan akhirat. ${ }^{19}$

Selain itu, Islam di kenal sebagai agama Rabbaniah (ketuhanan) Insaniyah (kemanusiaan), Syumuliah (universal atau rahmatan lil alamin), Waqi'iyah (kontekstual), Wasathiyah (moderat), dan Aqliyah (rasional) ${ }^{20}$ di mana Islam mengajarkan umatnya untuk memiliki akblakul al-karimah seperti tujuan utama di utusnya Rasulluah SAW yaitu untuk menyempurnakan akhlak manusia baik memperbaiki hubungan makbluq dengan khaliq ataupun hubungan baik antara makbluq dengan makbluq. ${ }^{21}$

Namun, perjalanan hidup seseorang tidak terlepas dari sebuah permasalahan yang tengah dihadapinya. Hal ini tentu dapat mempengaruhi pemahaman

17 R. Abuy Sodikin, “Konsep Agama Dan Islam," Alqalam 20, no. 97 (2003): 1, https://doi.org/10.32678/alqalam.v20i97.643.

18 Sodikin.

19 Fauzah Nur Aksa, Modul Pendidikan Agama Islam, 1st ed. (Lhokseumawe: Unimal Press, 2015).

20 Baidhowi, "Islam Tidak Radikalisme Dan Terorisme," in Seminar Nasional Hukum Universitas Negeri Semarang, vol. 3, 2017, 197-218.

21 Syarifah Habibah, “Akhlak Dan Etika Dalam Islam,” Jurnal Pesona Dasar 1, no. 4 (2015): 7387. 
serta pengamalan agama yang mungkin dapat membawanya kepada fahaman yang bersifat radikalisme mahupun terorisme. Hal demikian inilah yang kemudian menimbulkan sebuah pertanyaan apakah agama Islam membenarkan serta membolehkan seseroang untuk melakukan tindakan terorisme, sedangkan disisi lain tampak jelas bahwa Islam merupakan agama yang membawa kedamaian serta keselamatan bagi seluruh umat di dunia. ${ }^{22}$

Tindakan terorisme atau pun radikalisme yang berujung pada tindakan merusak serta melahirkan teror kepada pihak lain merupakan tindaka tindakan yang telah melampaui batas baik secara pemahaman ideologi mahupun perbuatan dan utamanya ia telah menyampingkan kepentingan nilak akhlak. Seringkali pelaku terorisme meyakini bahwa tindakan mereka merupakan bagian dari jihad meskipun harus membuat dirinya dan pihak lain terbunuh. Hal tersebut terjadi karena mereka memahami makna jihad hanya dalam pengertian sempit di mana pengertian jihad hanya terbatas pada qital (peperangan) saja. ${ }^{23}$

Menurut falsafah Islam seperti Ibn Miskawayh menyatakan bahwa pembersihan jiwa manusia harus dilakukan untuk melahirkan akhlak yang berkualitas, kemudian melakukan jihad secara adil, cermat dan Iklhas. Akan tetapi, jihad yang dimaksud adalah jihad yang memfokuskan pada peperangan melawan hawa nafsu bukan jihad yang memfokuskan pada peperangan melawan senjata. Maka, budaya keganasan, radikalisme, dan juga terorisme bukanlah sesuatu perbuatan yang adil melaikan ia bentuk kekejaman yang tidak dianggap sebagai amalan jihad, tidak berakhlak, tidak beretika, dan tidak bermoral. ${ }^{24}$ Firman-Nya:

"Dan sesiapa yang membunuh seorang mukmin dengan sengaja, maka balasannya ialah neraka jahanam, kekal ia di dalamnya, dan Allah murka kepadanya, dan melakanatkannya serta menyediakan baginya azab seksa yang besar." (QS: an-Nisa: 93)

"Bahawasanya sesiapa yang membunuh seorang manusia dengan tiada alasan yang membolehkan membunuh orang itu, atau (kerana) melakukan kerosakan di muka bumi, maka seolah-olah dia telah membunuh manusia semuanya." (QS: al-Maidah: 32)

Dan hadis

"Siapa yang membunuh dirinya dengan cara tertentu di dunia maka dia akan disiksa pada hari kiamat dengan cara yang sama." ${ }^{25}$

22 Baidhowi, "Islam Tidak Radikalisme Dan Terorisme."

23 Zu Azmi Yaakob and Ahmad Sunawari Long, "Terorisme Sebagai Cabaran Ideologi Muslim Masa Kini: Satu Analisis Dari Perspektif Falsafah," International Journal of Islamic Thought 7 (2015): 58-63, www.ukm.my/ijit.

24 Azmi Yaakob and Sunawari Long.

25 Abul Husain Muslim bin al-Hajjaj al-Qusyairi. An-Naisaburi, Shabih Muslim, 1st ed. (Beirut: Dar al-Fikr, 2003). 
"Nabi Saw bersabda: di antara dosa-dosa besar adalah: Berbuat syirik terhadap Allah, durhaka terhadap kedua orang tua, membunuh diri, dan sumpah palsu." 26

"Nabi SAW bersabda: tidak halal bagi seseorang muslim menakut-nakuti muslim lainnya." 27

Berdasarkan dalil-dalil Al-Qur'an dan Hadits di atas, jelaslah bahwa perilkau radikalisme atau ekstremisme kekerasan tidak dapat dibenarkan dengan alasan atau argumen apa pun. Islam selalu melarang kekerasan atau berbuat kerusakan di muka bumi. Oleh karena itu, Islam tentu saja melarang penyalahgunaan agama untuk tujuan negatif, karena esensi dari tujuan beragama manusia untuk menyebarkan manfaat dan menanam kebaikan di tanah, karena dengan menanam kebaikan, anda akan menuai kebaikan, dan jika menanam kejahatan, akan menuai kejahatan juga. ${ }^{28}$ Maka jelas bahwa Islam adalah agama yang jauh dari kekerasan, ekstremisme atau budaya terorisme baik dalam bentuk bom bunuh diri atau bentuk lainnya, dan untuk tujuan apa $\operatorname{pun}^{29}$ karena tindakan tersebut melanggar perintahNya. ${ }^{30}$

\section{Peranan Wanita dalam Mencegah Terorisme dan Radikalisme}

Istilah teror tidaklah asing bagi bangsa Indonesia di mana terorisme bukanlah fenomena baru di Indonesia. ${ }^{31}$ Kegiatan aksi terorisme yang berlaku pada saat ini lebih dominan kepada sentimen agama di mana sebagian individu atau golongan berkeyakinan bahawa banyak daripada umat Islam mengalami degredasi moral dan sosial akibat daripada memercayai dogma dan praktik religi yang menyimpang. Hal ini yang kemudian melahirkan berbagai aktifitas radikalisme karena sebagian golongan merasa bahwa banyak daripada muslin Indonesia telah melalaikan serta tidak lagi merujuk pada kesucian serta orisinalitas panduan agama. ${ }^{32}$

Berbagai peristiwa radikal yang berujung kepada aksi-aksi terorisme seperti bom bunuh diri dan lain sebagainya telah menganggu rasa aman hidup masya-

26 An-Naisaburi.

27 As-Sijstani. Abu Dawud Sulaiman bin Al-Asy'ats, Sunan Abu Dawnd. Tahqiq: Abdul Latif Hirzallah, 1st ed. (Damaskus: Dar Ar-Risalah Al-Alamiah, 2009).

28 A M Fatwa, “Terorisme Global Dalam Perspektif Islam," Jurnal Tarjïh 9, no. 1 (2007): 91102, https://jurnal.tarjih.or.id/index.php/tarjih/article/view/72/73.

29 Ramlani Lina Sinaulan, "Islamic Law and Terrorism in Indonesia," International Journal of Nusantara Islam 4, no. 1 (2016): 13-28, https://doi.org/10.15575/ijni.v4i1.1436.

30 Kholid Hidayatullah, "Kajian Islam Tentang Terorisme Dan Jihad," Al Hikmab: Jurnal Studi Keislaman 6, no. 1 (2016): 85-102.

31 Tukina Tukina, “Tinjauan Kritis Sosial: Terorisme Di Indonesia,” Humaniora 2, no. 1 (2011): 731-42, https://doi.org/10.21512/humaniora.v2i1.3090.

32 Azyumardi Azra, "Bali and Southeast Asian Islam: Debunking the Myths", Di Kumar Ramakrishna Dan See Seng Tan (Editor), After Bali: The Threat of Terrorism, Institute of Defence and Strategic Studies" (Nanyang Technological University, 2003). 
rakat. Apalagi sekarang ini wacana intoleran dan faham radikal atas nama agama semakin meluas dan terinternalisasi ke dalam lingkaran masyarakat. ${ }^{33}$ Oleh karena itu, berbagai upaya dan upaya telah dilakukan untuk mencegah agar perilaku tersebut tidak terulang kembali, termasuk partisipasi perempuan dalam upaya dan upaya tersebut. ${ }^{34}$

Dewasa ini, kaum wanita menempati kedudukan yang strategis di mana mereka mampu menjadi inspirator sekaligus motivator kepada kaum laki-laki. Wanita modern di era sekarang pun dikehendaki untuk memiliki pemikiran yang progresif, aktif, partisipatif, berpendidikan, berfikir global dan bertindak lokal serta peduli terhadap permasalahan-permasalahan tengah dihadapi masyarakat, umat, ataupun negara ${ }^{35}$ tidak terkecuali terhadap persoalan radikalisme dan terorisme saat ini.

Wanita adalah figur utama dalam menciptakan keluarga yang harmonis di mana kemuliaan dan keselamatan dimulai dari keluarga itu sendiri. Seorang anak adalah anugerah besar, amanah dari Tuhan yang mesti di jaga, dan di didik agar menjadi orang-orang yang sukses dalam hidup ini baik di masa sekarang ataupun di masa yang akan datang dan orang tua ialah pendidik utama dan pertama dalam lingkaran keluarga, mereka dapat menanamkan akidah dan perilaku sikap yang baik kepada anak-anaknya selaras dengan yang di syariatkan oleh agama. ${ }^{36}$

Seorang anak membutuhkan lingkungan yang memungkinkan mereka untuk mengembangkan berbagai potensi, baik potensi fisik dan biologis, potensi intelektual, potensi sosial, maupun potensi emosional. Oleh karena itu, ibu merupakan orang yang paling dekat dan perlu memberikan stimulasi dan bimbingan agar potensi-potensi tersebut dapat digunakan secara normal ke arah yang baik dan benar. ${ }^{37}$ Firman-Nya:

"Dan hendaklah takut kepada Allah orang-orang yang seandainya meninggalkan dibelakang mereka anak-anak yang lemah, yang mereka khawatir terhadap (kesejahteraan) mereka. Oleh sebab itu hendaklah mereka bertakwa kepada Allah dan hendaklah mereka mengucapkan perkataan yang benar." (Q.S: An-Nisa: 9)

Harus dipahami bahwa seseorang tidak akan menjadi teroris dalam sekejap, tetapi akan mengadopsi narasi yang tidak toleran dan radikal terlebih dahulu. Pada saat yang sama, organisasi teroris menyebarkan propaganda dan narasi sen-

33 Pujiyanto, "Peran Perempuan Strategis Dalam Pencegahan Radikalisme"," Kemenag.Go.Id, n.d.,https://kemenag.go.id/berita/read/505858/peran-perempuan-strategis-dalampencegahan-radikalisme, diakses pada 03 May 2020, 13:55pm.

34 Idrus Ruslan, "Islam Dan Radikalisme: Upaya Antisipasi Dan Penanggulangannya," Kalam 9, no. 2 (2015): 215-32, https://doi.org/10.24042/klm.v9i2.329.

35 Rahimah Embong \& Ferayanti Zikriati, "Wanita Dalam Perspektif Islam," BITARA International Journal of Civilizational Studies and Human Sciences 1, no. 2 (2018): 52-59.

36 Zikriati.

37 Zikriati. 
timen dan kebencian berdasarkan perbedaan agama sebagai bagian dari upaya mereka untuk meradikalisasi masyarakat. Dengan kemajuan teknologi saat ini, informasi dan narasi tentang intoleransi, radikalisme dan terorisme, tidak hanya berlaku di dunia offline, tetapi juga menyebar di dunia maya.

Namun, jika bisa diimbangi dengan pendidikan dan agama yang kuat, radikalisme, ektremisme kekerasan bahkan terorisme tidak mungkin terjadi. $\mathrm{Na}$ mun, keberhasilan penanggulangan persoalan tersebut tidak terbatas pada tataran kebijakan pemerintah, tetapi juga berada pada unit kecil yang disebut keluarga sebagai benteng utama dalam melawan paham radikal melaui peran perempuan dalam keluarga khususnya dalam pendidikan dan literasi anak-anaknya, untuk menghindari konsep kekerasan dan terorisme yang sangat berbeda dengan ajaran agama manapun. ${ }^{38}$ Dengan demikian, wanita memiliki peran yang sentral dalam mendidik penerus mereka untuk menjadi para pemimpin yang memiliki jiwa nasionalisme yang kuat. ${ }^{39}$ Dan pendidikan agama dalam keluarga adalah pondasi yang harus ditanamkan. ${ }^{40}$

Seorang penyair, Hafiz Ibrahim menytakan bahwa "Al-Ummu madrasatul ula, iza a'dadtaha a'dadta sya'ban thayyibal a'raq" bermaksud 'ibu adalah madrasah (Sekolah) pertama bagi anaknya. Jika engkau persiapkan ia dengan baik, maka sama halnya engkau persiapkan bangsa yang baik pokok pangkalnya." ${ }^{41}$

Karenanya, sosok perempuan menjadi tokoh utama dan pertama yang mampu mengajarkan nilai-nilai agama yang mulia agar mampu membentuk karakter, perilaku dan kebiasaan yang bersifat moderat kepada anak sejak usia dini. ${ }^{42}$ Maka, tidak dapat dinafikan bahwa posisi wanita sangat vital dalam keluarga. Figur perempuam merupakan kunci kebaikan dan toleransi bagi anakanaknya yaitu dengan memberikan pendidikan, edukasi, serta pemahaman kepada mereka mengenai pentingnya persatuan, nasionalisme, pemahaman religi yang benar berikan kasih saying yang lebih ${ }^{43}$ serta wawasan mengenai kearifan lokal

38 Fithriani Gade, "Ibu Sebagai Madrasah Dalam Pendidikan Anak," Jumal Ilmiah Didaktika 13, no. 1 (2012): 31-40, https:// doi.org/10.22373/jid.v13i1.462.

39 Musyafak, "Peran Perempuan Dalam Pencegahan Radikalisme."

40 Nanang Hasan Susanto, "Menangkal Radikalisme Atas Nama Agama Melalui Pendidikan Islam Substantif," Nadwa: Jurnal Pendidikan Islam 12, no. 1 (2018): 65-88, https://doi.org/10.21580/nw.2018.12.1.2151.

41 Bahrul Ulum, "Al Ummu Madrasatul Ula, Itulah Sosok Ibu Sebagai Penerang Ilmu," Kompasiana.Com, n.d.

42 Fernan Rahadi, "Perempuan Punya Pean Penting Pencegahan Radikalisme," Republika.Com, n.d., https://www.republika.co.id/berita/nasional/umum/18/07/05/pbe5sr291-perempuan -punya -peran-penting-pencegahan-radikalisme, diakses pada 03 May 2020, 07:54am.

43 Sri Nuraini, "Perempuan Berperan Aktif Menangkal Radikalisme”, Kompasiana.Com:," Kompas.Com, n.d., https://www.kompasiana.com/sri.nuraini/5c8e6c0a95760e6eb16421a3/perempuanberperan-aktif-menangkal-radikalisme, diakses pada 03 May 2020, 08:04am. 
sejak usia dini ${ }^{44}$ yang akhirnya terbentuk upaya pencegahan radikalisme dan terorisme, ${ }^{45}$ Firman-Nya:

"Hai orang-orang yang beriman, peliharalah dirimu dan keluargamu dari api neraka yang bahan bakarnya adalah manusia dan batu."'(Q.S:AtTahrim:6)

Dan Rasullulah SAW bersabda:

"Ketahuilah setiap kalian adalah pemimpin, dan setiap kalian akan dimintai pertanggungjawaban atas yang dipimpin, penguasa yang memimpin manusia dia akan dimintai pertanggungjawaban atas yang dipimpinnya, seorang lelaki (kepala keluarga) adalah pemimpin keluarganya dan dia dimintai pertanggungjawaban atas yang dipimpinnya,dan wanita atau istri adalah pemimpin atas penghuni rumah suaminya dan anaknya, dan dia bertanggung jawab atas mereka." ${ }^{46}$

Selain itu, wanita tidak hanya berperan penting dalam urusan kekeluargaan saja, mereka juga memaikan peranan penting dalam lingkungan masyarakat sekitar dan negara. Karena itu, wanita memiliki tanggung jawab yang besar baik dalam pembentukan maupun pembangunan keluarga serta masyarkat Islam secara umumnya ${ }^{47} \mathrm{Hal}$ ini terbukti di mana banyak dari kaum wanita di era sekarang menempati kedudukan serta memegang posisi penting baik dalam lingkaran masyarakat maupun pemerintah. ${ }^{48}$

Karenanya, kepemimpinan mereka menjadi pilar yang penting baik dalam ruang lingkup keluarganya maupun instansi kemasyarakatan dalam rangka pemberdayaan bangsa sehingga mampu melahirkan generasi insan yang mulia bagi membangun bangsa. ${ }^{49}$ Tanggung jawab pembinaan keluarga dibagi antara orang tua, masyarakat, pemerintah, dan negara. Oleh karena itu, keluarga dapat me-

44 Adam Prawira, "Peran Penting Ibu Bentengi Keluarga Dari Ancaman Radikalisme," Sindonews.Com, n.d., https://nasional.sindonews.com/berita/1447975/14/peran-penting-ibubentengi-keluarga-dari-ancaman-radikalisme, diakses pada 03 May 2020, 08:13am.

45 Suhardi Alius, "Perempuan Memiliki Peran Penting Dalam Pencegahan Radikalimse Dan Terorisme," Tribunnews, 2020, tribunnews.com: https://www.tribunnews.com/ metropolitan /2018/07/05/suhardi-alius-perempuan-memiliki-peran-penting-dalam-pencegahanradikalisme-dan-terorisme.

46 Abu Abdillah Muhammad bin Ismail. Al-Bukhari, Shabih Al-Bukhari, 1st ed. (Beirut: Dar Ibn Katsir, 2002).

47 Husna Rahman, Izhar Kashim, and Adnan Pitchan, "Peranan Wanita Dalam Institusi Kekeluargaan: Perbincangan Dari Perspektif Islam.," Journal of Social Sciences and Humanities 12, no. 3 (2018): 1-16.

48 Muhd Imran Abd Razak et al., "Fiqh Jihad Wanita Dalam Konteks Kontemporari," Jurnal 'Ulwan 4 (2019): 37-48.

49 Tasnim Abdul Rahman, "Kepemimpinan Wanita Dari Kacamata Islam," in Proceeding: International Seminar on Al-Quran in Contemporary Society (Univerisiti Sultan Zainal Abidin (UniSZA), 2018). 
mantau perilaku, tindakan, dan pikiran yang tidak normal sebelum autoriti pemerintah terkait mengambil tindakan. ${ }^{50}$

Berdasarkan hasil pengamatan penulis, proses radikalisme dapat terjadi di lingkup yang paling kecil yaitu di dalam keluarga sehingga membendung paham radikalisme dan terorisme tidak bisa dilakukan hanya dalam ruang lingkup masyarakat dan negara saja, akan tetapi harus dilakukan dari basis paling dasar terlebih dahulu yaitu keluarga baik melalui peran seorang ayah ataupun ib dengan cara melakukan penguatan dan kontrol pengawasan di lingkup keluarga. Apalagi di era globalisasi saat ini ketika kehidupan sosial serta pergaulan semakin terbuka luas sehingga amat memerlukan pengawasan serta kasih saying dari kedua figur terdekat dalam sebuah keluarga, ayah dan ibu. Dengan kedudukan serta perenan strategi yang dimiliki oleh sosok wanita dalam keluarga, maka diharapkan berbagai pemikiran, ajaran, aliran serta pemahaman yang bersifat radikalisme yang mampu berujung kepada terorisme dapat terbendung dan dapat dicegah.

\section{Kesimpulan}

Radikalisme yang mengarah kepada tindakan terorisme merupakan kejahatan yang luar biasa, menghancurkan rasa aman dan damai bagi pihak lain dan merugikan pihak lain baik secara jiwa, harta dan lain sebagainya. Maka, salah satu upaya menanggulangi fenomena kekerasan radikalisme dan terorisme ialah dengan memaksimalkan peran potensial perempuan dalam membina keluarga agar senantiasa sejalan dengan nilai-nilai kemanusiaan sebagaimana yang diajarkan oleh semua agama terutama Islam, diharapkan mampu menghentikan gerakan terorisme di Indonesia. Peran potensi perempuan yang dapat dilakukan di dalam keluarga yaitu melaksanakan pendidikan dasar keagamaan, pendidikan kekeluargaan, dan pendidikan kemandirian.

\section{Daftar Pustaka}

Abdullah, Anzar. "Gerakan Radikalisme Dalam Islam: Perspektif Historis." Addin 10, no. 1 (2016): 1-28. https://doi.org/10.21043/addin.v10i1.1127.

Aksa, Fauzah Nur. Modul Pendidikan Agama Islam. 1st ed. Lhokseumawe: Unimal Press, 2015.

Al-Asy'ats, As-Sijstani. Abu Dawud Sulaiman bin. Sunan Abu Dawnd. Tahqiq: Abdul Latif Hirzallah. 1st ed. Damaskus: Dar Ar-Risalah Al-Alamiah, 2009.

Al-Bukhari, Abu Abdillah Muhammad bin Ismail. Shahih Al-Bukhari. 1st ed. Beirut: Dar Ibn Katsir, 2002.

Alius, Suhardi. "Perempuan Memiliki Peran Penting Dalam Pencegahan Radikalimse Dan Terorisme." Tribunnews, 2020. tribunnews.com:https://

50 Sapto Waluyo. Susetyo, Heru, Menangkal Terorisme, Chapter: Menangkal Terorisme Dengan Pendekatan Ketahanan Keluarga, 1st ed. (Surabaya: Pustaka Saga, 2018). 
www.tribunnews.com/metropolitan/2018/07/05/suhardi-aliusperempuan-memiliki-peran-penting-dalam-pencegahan-radikalisme-danterorisme.

Alwi, Abdullah Haji Hassan. "Islam Dan Wanita." Jurnal Usuluddin 4, no. 4 (2015): 105-16.

An-Naisaburi, Abul Husain Muslim bin al-Hajjaj al-Qusyairi. Shabih Muslim. 1st ed. Beirut: Dar al-Fikr, 2003.

Azmi Yaakob, Zu, and Ahmad Sunawari Long. "Terorisme Sebagai Cabaran Ideologi Muslim Masa Kini: Satu Analisis Dari Perspektif Falsafah." International Journal of Islamic Thought 7 (2015): 58-63. www.ukm.my/ijit.

Azra, Azyumardi. "Bali and Southeast Asian Islam: Debunking the Myths", Di Kumar Ramakrishna Dan See Seng Tan (Editor), After Bali: The Threat of Terrorism, Institute of Defence and Strategic Studies." Nanyang Technological University, 2003.

Badawi, Jamal. "The Status of Women in Islam." Journal Al-Ittihad 8, no. 2 (1971).

Baidhowi. "Islam Tidak Radikalisme Dan Terorisme." In Seminar Nasional Hukum Universitas Negeri Semarang, 3:197-218, 2017.

Fatwa, A M. “Terorisme Global Dalam Perspektif Islam.” Jurnal Tarïh 9, no. 1 (2007): 91-102. https://jurnal.tarjih.or.id/index.php/tarjih/article/view/ $72 / 73$.

Gade, Fithriani. "Ibu Sebagai Madrasah Dalam Pendidikan Anak." Jurnal Ilmiah Didaktika 13, no. 1 (2012): 31-40. https://doi.org/10.22373/jid.v13i1.462.

Habibah, Syarifah. "Akhlak Dan Etika Dalam Islam.” Jurnal Pesona Dasar 1, no. 4 (2015): 73-87.

Hamzah, Arief Rifkiawan. "Radikalisme Dan Toleransi Berbasis Islam Nusantara." Sosiologi Reflektif 13, no. 1 (2018): 19-35. http://ejournal.uinsuka.ac.id/isoshum/sosiologireflektif/article/view/131-03/1297.

Hidayatullah, Kholid. "Kajian Islam Tentang Terorisme Dan Jihad." Al Hikmah: Jurnal Studi Keislaman 6, no. 1 (2016): 85-102.

Husna Rahman, Izhar Kashim, and Adnan Pitchan. "Peranan Wanita Dalam Institusi Kekeluargaan: Perbincangan Dari Perspektif Islam." Journal of Social Sciences and Humanities 12, no. 3 (2018): 1-16.

Laisa, Emna. "Islam Dan Radikalisme." Islamuna: Jurnal Studi Islam 1, no. 1 (2014): 1-18. https://doi.org/10.19105/islamuna.v1i1.554.

Masyhar, Ali, and Ridwan Arifin. "Urgensi Pembentengan Masyarakat Dari Radikalisme Dan Terorisme (Upaya Terhadap Jamiyyah Nahdlatul Ulama Kecamatan Bonang Kabupaten Demak)." Jurnal Pengabdian Hukum Indonesia (Indonesian Journal of Legal Community Engagement) JPHI 1, no. 01 
(2018): 1-12. https://journal.unnes.ac.id/sju/index.php/JPHI/article/ view/27259.

Mubarak, Zulfi. "Fenomena Terorisme Di Indonesia." Salam: Jurnal Studi Masyarakat Islam 15, no. 2 (2012): 240-54.

Musyafak, Najahan. "Peran Perempuan Dalam Pencegahan Radikalisme." Jurnal Dakwah 21, no. 1 (2020): 85-110. https://doi.org/10.14421/jd.2112020.6.

Naharong, Abdul Muis. "Terorisme Atas Nama Agama." Refleksi 13, no. 5 (2014): 593-622. https://doi.org/10.15408/ref.v13i5.915.

Nuraini, Sri. "Perempuan Berperan Aktif Menangkal Radikalisme", Kompasiana.Com:" Kompas.Com, n.d. https://www.kompasiana.com/ sri.nuraini/5c8e6c0a95760e6eb16421a3/perempuan-berperan-aktifmenangkal-radikalisme, diakses pada 03 May 2020, 08:04am.

Prawira, Adam. "Peran Penting Ibu Bentengi Keluarga Dari Ancaman Radikalisme." Sindonews.Com, n.d. https://nasional.sindonews.com /berita/1447975/14/peran-penting-ibu-bentengi-keluarga-dari-ancamanradikalisme, diakses pada 03 May 2020, 08:13am.

Pujiyanto. "Peran Perempuan Strategis Dalam Pencegahan Radikalisme",." Kemenag.Go.Id, n.d. https://kemenag.go.id/berita/read/505858/peranperempuan-strategis-dalam-pencegahan-radikalisme, diakses pada 03 May 2020, 13:55pm.

Rahadi, Fernan. "Perempuan Punya Pean Penting Pencegahan Radikalisme." Republika.Com, n.d. https://www.republika.co.id/berita/nasional /umum/ 18/07/05/pbe5sr291-perempuan-punya-peran-penting-pencegahanradikalisme, diakses pada 03 May 2020, 07:54am.

Rahman, Asyraf Hj Ab, Wan Ibrahim Wan Ahmad, and Zainab Ismail. "Peranan Wanita Dalam Pembangunan Keluarga Dari Perspektif Fi Zilal AlQuran.” JGD-Journal of Governance and Development 6 (2010): 14-21. http://repo.uum.edu.my/11919/1/13.pdf.

Rahman, Tasnim Abdul. "Kepemimpinan Wanita Dari Kacamata Islam." In Proceeding: International Seminar on Al-Quran in Contemporary Society. Univerisiti Sultan Zainal Abidin (UniSZA), 2018.

Rajagukguk, Christin. "Feminisme Kultural Dan Peran Perempuan Dalam Deradikalisasi Di Indonesia." Journal of International Relations 4, no. 4 (2018): 775-83.

Razak, Muhd Imran Abd, Mohd Anuar Ramli, Nurul Khairiah Khalid, Mukhamad Khafiz Abd Basir, Mohd Farhan Abd Rahman, and Ahmad Firdaus Mohd Noor. "Fiqh Jihad Wanita Dalam Konteks Kontemporari." Jurnal 'Ulwan 4 (2019): 37-48.

Riniti Rahayu, Luh, and Putu Surya Wedra Lesmana. "Potensi Peran Perempuan Dalam Mewujudkan Moderasi Beragama Di Indonesia." Pustaka: Jurnal 
Ilmu-Ilmu Budaya 20, no. 1 (2020): 31-37. https://doi.org/10.24843 /pjiib.2020.v20.i01.p05.

Ruslan, Idrus. "Islam Dan Radikalisme: Upaya Antisipasi Dan Penanggulangannya." Kalam 9, no. 2 (2015): 215-32. https://doi.org /10.24042/klm.v9i2.329.

Sa'ari, Che Zarrina binti, and Joni Tamkin bin Borhan. "Peranan Wanita Dalam Pengukuhan Akidah Umat Islam.” Jurnal Usuluddin 23, no. 24 (2015): 3550.

Sinaulan, Ramlani Lina. "Islamic Law and Terrorism in Indonesia." International Journal of Nusantara Islam 4, no. 1 (2016): 13-28. https://doi.org /10.15575/ijni.v4i1.1436.

Sodikin, R. Abuy. "Konsep Agama Dan Islam." Alqalam 20, no. 97 (2003): 1. https://doi.org/10.32678/alqalam.v20i97.643.

Susanto, Nanang Hasan. "Menangkal Radikalisme Atas Nama Agama Melalui Pendidikan Islam Substantif." Nadwa: Jumal Pendidikan Islam 12, no. 1 (2018): 65-88. https://doi.org/10.21580/nw.2018.12.1.2151.

Susetyo, Heru, Sapto Waluyo. Menangkal Terorisme, Chapter: Menangkal Terorisme Dengan Pendekatan Ketahanan Keluarga. 1st ed. Surabaya: Pustaka Saga, 2018.

Tukina, Tukina. "Tinjauan Kritis Sosial: Terorisme Di Indonesia." Humaniora 2, no. 1 (2011): 731-42. https://doi.org/10.21512/humaniora.v2i1.3090.

Ulum, Bahrul. "Al Ummu Madrasatul Ula, Itulah Sosok Ibu Sebagai Penerang Ilmu." Kompasiana.Com, n.d.

Yunus, A Faiz. "Radikalisme, Liberalisme Dan Terorisme: Pengaruhnya Terhadap Agama Islam.” Jurnal Studi Al-Qur an: Membangun Tradisi Berfikir Qur'ani 13, no. 1 (2017): 76-94. https://doi.org/10.21009/jsq.013.1.06.

Zikriati, Rahimah Embong \& Ferayanti. "Wanita Dalam Perspektif Islam." BITARA International Journal of Civilizational Studies and Human Sciences 1, no. 2 (2018): 52-59. terms and conditions of the Creative Commons Attribution Share Alike (CC BY SA) license (https://creativecommons.org/licenses/by-sa/4.0/). 